\title{
Jogos, Brincadeiras e Educação Infantil: notas acerca da construção de gênero ${ }^{1}$
}

\author{
Games, Plays and Childhood Education: notes about gender construction \\ Juegos, Juegos y Educación Infantil: notas sobre la construción de género
}

Recebido: 29/01/2021 | Revisado: 31/01/2021 | Aceito: 02/02/2021 | Publicado: 07/02/2021

\author{
Rosana Trindade de Matos \\ ORCID: https://orcid.org/0000-0003-1732-8013 \\ Universidade Federal do Amazonas, Brasil \\ rosanamatos83@gmail.com \\ Márcio de Oliveira \\ ORCID: https://orcid.org/0000-0003-4706-2930 \\ Universidade Federal do Amazonas, Brasil \\ márcio.1808@hotmail.com \\ Alícia Gonçalves Vásquez \\ ORCID: https://orcid.org/0000-0002-7867-2638 \\ Universidade Federal do Amazonas, Brasil \\ alicia03vasquez@gmail.com
}

\begin{abstract}
Resumo
O uso de jogos e brincadeiras no processo de aprendizagem de crianças pequenas é bastante recorrente no Brasil, de modo que as práticas pedagógicas acabam por fazer uso desses instrumentos para mediar o processo de ensino. A partir disso, o presente manuscrito discute acerca da função dos jogos e das brincadeiras na prática educativa da Educação Infantil, bem como a contribuição destes na construção do desenvolvimento e aprendizagens sobre gênero. Para alcançar ao objetivo, optamos por uma pesquisa bibliográfica e documental, caracterizando como um estudo qualitativo. Compreendemos que a Educação Infantil colabora para o desenvolvimento de processos emocionais, sociais e psicológicos da criança, o que abrange a compreensão acerca de si e do/a outro/a, incluindo as questões de gênero - aqui compreendidas como uma construção social, histórica, política e cultural. Como resultado, consideramos que os jogos e as brincadeiras são percebidos como atividades que, além de produzir o desenvolvimento amplo das crianças, estimulam o intercâmbio entre os pares, a resolver de forma construtiva os conflitos, a formação de um/a cidadão/cidadã com senso crítico e reflexivo. Junto a isso, concluímos que jogos e brincadeiras fazem com que as crianças pequenas tenham uma percepção maior da realidade e do ambiente que convivem, construindo conhecimentos sobre assuntos diversos, incluindo as questões de gênero.
\end{abstract}

Palavras-chave: Brincadeira; Jogos; Educação infantil; Gênero.

\begin{abstract}
The use of games and play in the learning process of young children is quite common in Brazil, so that pedagogical practices end up making use of these instruments to mediate the teaching process. From this, the present manuscript discusses the role of games and play in the educational practice of Early Childhood Education, as well as their contribution to the construction of development and learning about gender. To reach the objective, we opted for a bibliographic and documentary research, characterizing it as a qualitative study. We understand that Early Childhood Education contributes to the development of emotional, social and psychological processes of the child, which encompasses understanding about oneself and the other, including gender issues - here understood as a social, historical, political and cultural. As a result, we consider that games and play are perceived as activities that, in addition to producing the broad development of children, stimulate exchanges between peers, to resolve constructively conflicts, the formation of a citizen with critical and reflective sense. Along with this, we conclude that games and play make small children have a greater perception of the reality and the environment they live in, building knowledge on various subjects, including gender issues.
\end{abstract}

Keywords: Play; Games; Early childhood education; Gender.

\section{Resumen}

El uso de juegos y juegos en el proceso de aprendizaje de los niños pequeños es bastante común en Brasil, por lo que las prácticas pedagógicas terminan haciendo uso de estos instrumentos para mediar el proceso de enseñanza. A partir de ello, el presente manuscrito analiza el papel de los juegos y el juego en la práctica educativa de la Educación Infantil, así como su contribución a la construcción del desarrollo y el aprendizaje sobre género. Para alcanzar el

\footnotetext{
${ }_{1}$ Informamos que a construção do artigo teve apoio do Conselho Nacional de Desenvolvimento Científico e Tecnológico/CNPq, da Fundação de Amparo à Pesquisa do Estado do Amazonas/Fapeam e da Universidade Federal do Amazonas-UFAM
} 
objetivo, optamos por una investigación bibliográfica y documental, caracterizándola como un estudio cualitativo. Entendemos que la Educación Infantil contribuye al desarrollo de los procesos emocionales, sociales y psicológicos del niño, que engloba el entendimiento sobre uno mismo y el otro, incluyendo las cuestiones de género - aquí entendido como social, histórico, político y cultural. En consecuencia, consideramos que el juego y el juego se perciben como actividades que, además de producir el desarrollo amplio de los niños, estimulan los intercambios entre pares, para resolver de manera constructiva los conflictos, la formación de un ciudadano con sentido crítico y reflexivo. Junto a esto, concluimos que los juegos y el juego hacen que los niños pequeños tengan una mayor percepción de la realidad y el entorno en el que viven, construyendo conocimientos sobre diversos temas, entre ellos la problemática de género.

Palabras clave: Juego; Juegos; Educación infantil; Género.

\section{Introdução}

Brinquedos e jogos podem "transportar" as pessoas que brincam e jogam a uma cultura diferenciada, um momento diferente, a depender de como essas ações são organizadas. Esses instrumentos nos fazem imaginar como eram as pessoas, os costumes, as atividades de determinadas épocas. Nesse sentido, o jogo e as brincadeiras acabam por encantar as crianças pequenas, levando-lhes a criar e recriar, concretizando em movimento/ação suas fantasias, da mesma forma que podem lhes possibilitar reviver momentos do seu cotidiano, despertando os aspectos físicos, afetivos e sociais oportunizando o conhecimento de si, do/a outro/a e do seu meio. Nessa direção, Kishimoto (2014, p. 102) expõe que "[...] o jogo e a brincadeira fazem a tessitura com a imaginação, característica universal do brincar e do jogar. O lúdico só existe, quando brincantes assumem significados simbólicos em situações comunicativas”.

Para a Educação na infância, o essencial é o jogo e o brincar como linguagem de fácil acesso à criança pequena, o que pode tornar seu aprendizado mais rico e significativo neste espaço escolar, por isso elas devem brincar independentemente de suas condições físicas, intelectuais ou sociais, pois a brincadeira é essencial para a sua vida. E neste sentido queremos mostrar as possibilidades do aprendizado mais significativo entre a escola, o jogo, e a brincadeira na infância.

Percorrendo por este caminho, resgatar a cultura lúdica infantil, nos parece fundamental para quem convive com a infância, pois a criança adquire, constrói e constitui sua cultura lúdica brincando. Compartilhar com a criança nesta fase de escolarização, que é a Educação Infantil, estes momentos do brincar e do jogar requer dos/as professores/as, responsáveis, pesquisadores/as, disponibilidade para reviver o jogo, há muito tempo modificado e atualizado por consequência das exigências que o universo adulto nos impõe e pelo avanço da tecnologia.

Os jogos e as brincadeiras alegram e motivam as crianças, integrando-as e dando-lhes oportunidades de se sentirem felizes, trocarem experiências, ajudarem-se mutuamente, lidar com ganhos e perdas. De acordo com Valentim (2019), esta oportunidade desenvolve na criança autonomia, criatividade, responsabilidade, estruturação da consciência corporal, noção de espaço-temporal sendo o lúdico o principal procedimento metodológico numa perspectiva biopsicossocial da criança sem exclusões, sem estereótipos de que exista brincadeiras e jogos de meninas e de meninos. Já nas atividades brincantes, as crianças precisam perceber que tanto meninos como meninas são capazes de realizar diversas atividades, de maneira que tudo o que é direcionado à criança pequena pode ser aproveitado por eles e por elas.

No entanto, é comum, nas instituições escolares, professores/as segregar as atividades para meninos e para meninas. Isso fica visível no uso de jogos e no desenvolvimento de brincadeiras. A eles são ofertadas atividades mais competitivas, mais radicais, com objetos voltados para o ambiente aberto (bola, carrinho, espadas etc.). Enquanto que para elas são ofertadas atividades menos competitivas, menos radicais, com objetos voltados para o ambiente privado/fechado (casinha, boneca, imitações de afazeres domésticos etc.). Essa visão separatista ocorre a partir da percepção de mundo dos/as adultos/as, uma visão - muitas vezes - estereotipada, preconceituosa. Finco (2010, p. 122) afirma que "[...] homens e mulheres adultos educam crianças definindo em seus corpos diferenças de gênero", o que é perceptível nas demarcações entre os gêneros, nas proibições, 
no que é permitido a cada pessoa. Essa definição, a exemplo do que ocorre na sociedade como um todo, acaba por adentrar nos muros escolares.

É por meio do jogo e da cultura lúdica que a criança se desenvolve, pois eles possibilitam a elas dar vazão aos seus anseios e frustrações, permitindo interação social e conhecimento próprio. Tanto os jogos, quanto as brincadeiras, devem ter seu espaço no desenvolvimento infantil, visto que por meio deles as crianças ganham possibilidades de tomar decisões e fazer descobertas emocionais e físicas, e são em grupos que elas trocam informações e expressam suas vontades, o que também contribui de forma significativa para seu amplo desenvolvimento. Como problema do presente estudo, apresentamos a seguinte questão: Como jogos e brincadeiras podem contribuir na construção do gênero das crianças no contexto da Educação Infantil?

Assim, buscaremos enfatizar - por meio de uma pesquisa bibliográfica e documental - a relação do jogo e o brincar nas atividades de psicomotricidade na Educação Infantil para um melhor desenvolvimento de suas competências e habilidades. Para tanto, dividimos o manuscrito em três seções, a saber: (I) relacionando os jogos, a brincadeira na história da infância; (II) Jogos e brincadeiras infantis e (III) Jogos, brincadeiras e a construção de gênero na Educação Infantil.

\section{Caminhos Percorridos}

Optamos pela construção de uma pesquisa bibliográfica e documental, numa abordagem qualitativa. Utilizamos da análise documental por ser uma valiosa técnica para fazer a abordagem dos dados qualitativos (Gil, 2002). Os documentos analisados dizem respeito às características da Educação brasileira - Constituição da República Federativa do Brasil (Brasil, 1988), Lei de Diretrizes e Bases da Educação Nacional (Brasil, 1996) e Plano Nacional de Educação (Brasil, 2014). Além disso, perpassamos por documentos específicos que amparam os aspectos de direitos das crianças, a exemplo do Estatuto da Criança e do Adolescente (Brasil, 1990). Ainda nesse sentido, trouxemos à discussão documentos oficiais com a tratativa acerca de jogos, brincadeiras e gênero: Referencial Curricular Nacional (Brasil, 1998), Diretrizes Curriculares Nacionais Gerais da Educação Básica (Brasil, 2013).

Salientamos que os documentos oficiais pouco discutem os aspectos de gênero, quando muito, apresentam textos de maneira generalizada, o que permite a discussão com as crianças, no entanto, a letra dos documentos é - ainda - bastante superficial. Outrossim, com uma leitura atenta, ao estipular o combate às violências, ao indicar o trabalho do respeito às diferenças, ao ressaltar o trabalho do convívio entre as crianças, os documentos oficiais sinalizam práticas que envolvam discussões de gênero - sem mencionar a categoria. Para embasar mais especificamente o conceito e a prática pedagógica, autores/as renomados/as da área foram incluídos em nossa discussão e serão apresentados na sequência.

Ainda explicitamos que nos utilizamos de pesquisa bibliográfica por abranger referências já tornadas públicas em relação ao tema estudado, desde as revistas, livros, pesquisas, teses, monografias, dissertações (Gil, 2002). Aqui, em específico, amparamos as discussões em materiais relacionados a jogos e brincadeiras (Almeida, 1978; Brunelli, 1996; Kishimoto, 2016; Oliveira, 2012; Sommerhalder, 2011), características específicas de crianças (Ariès, 1981; Pinto, 1997; Rocha, 2002), aspectos da Educação Infantil (Kuhlmann, 2000) e questões de gênero (Carvalho, 2020; Felipe, 2013; Finco, 2010; Guerra, 2005; Louro, 2011; Meyer, 2013; Maio, Oliveira \& Peixoto, 2020).

Por fim, ainda ressaltamos o cunho qualitativo da presente pesquisa, que se deve pelo fato que, de acordo com Bodgan e Biklen (1982), ampara algumas especificidades: apresenta o ambiente natural como fonte de busca de dados; o/a pesquisador/a é o principal instrumento de coleta de dados; os dados obtidos e analisados são, em sua maioria, descritivos; há uma preocupação bastante considerável em relação ao processo; o significado que as pessoas dão aos objetos de pesquisa tem muita relevância.

Assim, todos esses temas - jogos e brincadeiras, especificidades das crianças pequenas, características da Educação Infantil e questões de gênero - permeiam a presente pesquisa em seus variados momentos: desde a introdução, perpassando 
pelo desenvolvimento e as considerações finais. Essa construção permitiu ampliar o leque de possibilidades de análise, relacionando os termos e conceitos, a fim de estabelecer que a Educação tem um papel valioso na formação das pessoas, devendo ser amparado por práticas científicas, contribuindo no desenvolvimento integral das crianças.

\section{Relacionando os Jogos e a Brincadeira na História da Infância}

Segundo Ariès (1981), na Idade Média a concepção de infância não era existente, e a escola por sua vez era de cunho religioso, a qual acolhia as crianças de qualquer idade sem distinções pelo o que hoje chamamos de série/ano. E somente a partir da Idade Moderna, passou-se a ter um olhar sobre as particularidades, identidade da criança se concretizando os rumos da Educação e da escola. "A criança era, portanto, diferente do homem, mas apenas no tamanho e na força, enquanto as outras características permaneciam iguais" (Ariès, 1981, p. 14). Sendo assim, a criança era tratada como um/a adulto/a em miniatura, trabalhavam nos mesmos locais e usavam os mesmos tipos de roupas de uma pessoa adulta, só que em uma versão menor.

No momento mais frágil da infância, enquanto "filhote de homem" (Rocha, 2002, p. 25), em que não podia cuidar de si sozinha, a passagem da criança pela família era breve e insignificante. Sendo vista como substituível, como um indivíduo produtivo com uma função utilitária para a sociedade, uma vez que, depois dos sete anos de idade era implantada na vida adulta, ajudando na vida econômica da família. Pois, realizava tarefas copiando seus/suas responsáveis e seguindo seus ofícios. Dessa forma, cumprindo seu papel na família e na sociedade.

A partir do século XV se vislumbrou uma mudança dessa organização de família e de escola, momento este com a Modernidade, fazendo com que estas duas instituições família e escola assumissem um papel formador com relação à criança. Neste mesmo século XV a infância é vista como um período da vida do ser humano, a escola que até então era indiferente à formação infantil, passa a fazer a diferenciação das idades, criando as classes escolares. Como descreve Cambi (1999, p. 203):

[...] é delegado um papel cada vez mais definido e mais decisivo, de tal modo que elas se carregam cada vez mais de uma identidade educativa, de uma função ligada não só ao cuidado e ao crescimento do sujeito em idade evolutiva ou à instrução formal, mas também à formação pessoal e social ao mesmo tempo.

Dessa maneira, percebemos que começa a existir uma identidade educativa. Sendo, que existe uma função agora não somente voltada ao cuidar ou à formação instrutiva. Mas, também a formação pessoal e social. Pois, precisamos pensar a criança como um ser em sua totalidade, com seus questionamentos, que deslumbra a sociedade onde vive. E com as atualizações de pesquisas e estudos voltados sobre a criança e a infância vem surgindo novos conceitos, trazendo uma identidade mais consistente do ser criança e da infância. Destacamos os/as autores/as Pinto (1997), Kishimoto (1992; 2016) que em seus estudos e investigações descrevem que as crianças são indivíduos capazes, que consomem e reproduzem cultura, possuem uma história, são sujeitos do processo de socialização e não objetos da socialização do/a adulto/a, bem como o próprio Estatuto da Criança e do Adolescente (Brasil, 1990) o qual reconhece a criança como sujeito de direitos.

Nos estudos de Kishimoto (1992; 2016) e Schwartz (1998), o século XVI é caracterizado pelo início das tentativas de associar o jogo e a brincadeira à Educação da criança. Esse movimento das transformações sociopolíticas e pedagógicas foram iniciadas no século XVII, sendo que o século XVIII representa um marco importantíssimo na nossa história. Neste período, um dos maiores teóricos do século XVIII chamado Rousseau (1756) que radicalmente influenciou na pedagogia o modo de ver a criança, colocando-a no centro, ressaltando a necessidade de se conservar na criança o seu caráter infantil, de tal forma que a Educação das crianças deveria acontecer de forma natural, longe das influências da sociedade e sob a orientação de um pedagogo garantindo que sua Educação esteja de acordo com a natureza. "Isso implicaria num brincar valorizado como atividade própria da criança, que se marca uma ruptura da representatividade da imagem que se tinha da criança” (Rousseau, 
1999, p. 68), ou seja, a criança é dotada de valor positivo e de uma natureza boa. A criança é colocada definitivamente no centro da família e da sociedade, acontecimentos estes permeados no final do século XVIII e início do século XIX.

Nesse novo cenário, o jogo acompanha igualmente essa imagem inocente e pura da criança. É a partir desse período da história que de fato o jogo é inserido nas escolas como espaço de Educação da primeira infância, ou seja, um espaço de desenvolvimento para a criança brincar naturalmente. Com Friedrich Fröebel (1782-1852) segundo os estudos de Kishimoto (1992), constrói sua proposta pedagógica para a Educação da criança pequena e com este vem a concepção de infância, a criação dos jardins de infância e o método fröbeliano, fazendo do jogo não mais visto como espaço de recreação, mas como espaço natural e eficaz do desenvolvimento físico, mental e moral da criança, além de revelar e definir a individualidade e personalidade infantil.

No que se refere à Educação destas crianças no Brasil, Kuhlmann Junior (2000) destaca que as instituições educacionais começam a se reorganizar a partir da segunda metade do século XIX, compondo-se da creche e dos jardins de infância. Este jardim de infância chega ao Brasil com uma perspectiva educativa que traz consigo a proposta fröebeliana para a Educação da criança pequena. Porém com o processo de alfabetização, a leitura e a escrita se tornam pontos fundamentais da Educação da criança pré-escolar. O jogo sucumbe a essa nova necessidade da Educação Infantil. Kuhlmann Junior (2000, p. 59) compreende que

[...] ainda hoje há crianças pequenas que são submetidas a uma disciplina escolar arbitrária em que, diferentemente de um compromisso com o conhecimento, a instituição considera não ser sua função prestar os cuidados necessários e sim controlar os alunos para que sejam obedientes à autoridade.

Nos dias atuais, o jogo é percebido de forma equivocada por alguns/algumas professores/as, quando confundem o conceito de jogos, em que geralmente a criança fica solta e faz uma escolha aleatória da atividade, sem um direcionamento do/a docente. Oliveira (2012, p. 34) escreve que “[...] uma proposta que contemple jogos para a Educação Infantil, deve ter o cuidado de oferecer as atividades específicas (jogos e brincadeira); mas também as interações entre crianças e crianças, entre crianças e seus professores" essas reflexões descreve a postura do/a professor/a mediante o brincar e o jogar, e ele/a não ser um/a mero/a controlador/a.

Na sociedade contemporânea, a infância é assinalada pelo brincar, que nos dias atuais, devido ao trabalho infantil na sociedade de baixa renda, é cada vez mais reduzido. Dessa forma, com desenvolvimento de pesquisas sobre brincadeiras, como instrumento para auxiliar no processo de ensino e aprendizagem, o Referencial Curricular Nacional para a Educação Infantil (Brasil, 1998, p. 63), aponta que “[...] a brincadeira está colocada como um dos princípios fundamentais, defendida como um direito, uma forma particular de expressão, pensamento, interação e comunicação entre as crianças”. Assim, Almeida (1978, p. 85) escreve que:

Etimologicamente a palavra JOGO vem do latim LOCUS, que significa gracejo, zombaria e que foi empregada no lugar de ludus: brinquedo, jogo, divertimento, passatempo. [...] os jogos não devem ser fins, mas meios para atingir objetivos. Estes devem ser aplicados para o benefício educativo. Os jogos devem ser construídos de atividades permanentes nos espaços da Educação Infantil, pois por meio deles é possível que a criança trabalhe de forma integral, ou seja, nos aspectos físicos, psicológicos, cognitivos e sociais.

Desse modo, simbolicamente no jogo, algumas proeminências admitem alcançar informações a respeito das crianças. Sendo citadas por Brunelli (1996, p. 167):

Combinações simples - Fernanda conversa com um pedaço de madeira: "ta bom, eu vou te dar comida". Ela usa o objeto para representar a criança com fome. Combinações compensatórias - proibido de subir a escada, Malthus cria um personagem que subirá a escada. Usa a fantasia para enfrentar a frustração. Combinações liquidantes - Fabiana, ao 
cair, diz para si mesma: "não foi nada" para encarar a situação de desprazer. Combinações simbólicas antecipatórias Thiago presencia um assalto (cena real), depois conta que seu pai bateu no assaltante até sangrar (imaginário). Ele tenta entender a violência e a importância do pai como protetor. Combinações simbólicas ordenadas - brincar de preparar batizados e aniversários implica ordenação, arrumação, organização e sequência. É uma tentativa de organizar a realidade.

Também devemos pensar nos jogos de exercícios, efetivados com o próprio corpo da criança, começando com movimentos simples e prosseguindo para os mais difíceis. Assim, jogos sensoriais, que instigam os experimentos sensoriais e a capacidade criadora da criança. E os jogos de linguagem, que ajudam na comunicação, como por exemplo, rodas, canções, apresentações faladas. Nesse momento as crianças começam a jogar juntas e a constituir regras, como as brincadeiras de pegapega, amarelinha e queimada.

Com todo o aporte teórico descrito acima percebemos os grandes avanços em relação à infância, a Educação na Infância e a utilização do brincar e dos jogos inseridos na escola. Estas oportunidades no momento atual desenvolveram na criança autonomia nas atividades de motricidades fina (escrita), a criatividade nas atividades de artes como pintura, nas dramatizações, a responsabilidade nos cuidados com os livros utilizados e o desejo de narrar a história para seus/suas colegas, a estruturação da consciência corporal, noção de espaço-temporal sendo o lúdico o principal procedimento metodológico numa perspectiva biopsicossocial da criança sem exclusões.

Adotar o brincar, o jogar como eixo da proposta curricular significa como diz Sommerhalder (2011, p. 63) “[...] é fundamental para a criança na medida em que ela se desenvolva como ser humano, é uma prática significante, por meio do qual, o sujeito se constitui, atinge o outro e se faz reconhecer por este”. Nesse sentido, uma Educação baseada nos jogos e nas brincadeiras torna o aprendizado mais natural, acessível, lúdico. A seguir discutiremos que com todo avanço dos jogos e das brincadeiras nos espaços familiares, houve sua evolução também no espaço escolar.

\section{Jogos e Brincadeiras Infantis}

Percebemos no cotidiano que é da natureza da criança o gosto pelo brincar. Durante o brincar ela desenvolve habilidades cognitivas e sociais, que viabilizam a importância do estudo pedagógico do despertar do seu conhecimento por meio de brincadeiras e jogos. Kishimoto (2016, p. 7) faz uma diferenciação quando o "[...] brinquedo será entendido sempre como objeto e em outra dimensão como objeto cultural, suporte de brincadeira, brincadeira como a descrição de uma conduta estruturada, com regras, e jogo infantil para designar tanto o objeto como regras do jogo da criança (brinquedos e brincadeira)".

Sendo assim, a atividade lúdica vem apropriando-se de um amplo lugar na Educação Infantil. O brincar é o cerne da infância e seu uso possibilita o trabalho pedagógico que admite a produção do conhecimento, além de estimular a afetividade na criança. Junto a isso, jogar e brincar podem contribuir diretamente no desenvolvimento de habilidades e valores, além de contribuir na organização do pensamento crítico, observando o seu redor, a capacidade dos/as colegas, as dificuldades apresentadas. Pois, o emprego educativo da brincadeira permite a aprendizagem do indivíduo, seus saberes, seus conhecimentos e sua concepção do mundo. Consequentemente, trabalhar as disciplinas por meio de atividades lúdicas, proporcionam um envolvimento maior, o que beneficia a edificação de significados de noções próprios do mundo da criança.

Assim, o brincar e o jogar fazem parte da vida da criança em qualquer idade e não deve ser percebida exclusivamente como divertimento, podendo promover a aprendizagem, cooperar no processo de desenvolvimento social e cultural, colaborar para uma boa saúde mental, para a comunicação, expressão, socialização e edificação de conhecimento. Dessa forma, as diferentes manifestações dessa linguagem foram surgindo, como a dança, o jogo, as brincadeiras, as práticas esportivas, nas quais se faz uso de diferentes gestos, posturas e expressões corporais com intencionalidade e que ao brincar, jogar, imitar e 
criar ritmos e movimentos, as crianças também se apropriam do repertório da cultura corporal na qual estão inseridas (Brasil, 1998).

As atividades lúdicas são a essência da infância, por isso, ao abordar este tema não podemos deixar de nos referir também à criança. Ao retornar a história e a evolução do ser humano na sociedade, percebemos que a criança nem sempre foi considerada como é hoje. Antigamente, ela não tinha existência social, era considerada miniatura do/a adulto/a, ou quase adulto/a. Seu valor era relativo, nas classes altas era educada para ter um prestígio na sociedade e nas classes baixas o valor da criança iniciava quando ela podia ser útil ao trabalho, colaborando na geração da renda familiar.

Brincar possibilita o desenvolvimento infantil, uma vez que a brincadeira expande a probabilidade de ponderar e de agir no seu cotidiano. Assim, brincar não é somente entretenimento, e sim uma atividade que lhe admite trabalhar com conhecimentos, angústias, fantasias e sonhos. Piaget (1988, p. 78), afirma: "Uma grande parte dos educadores da faixa de 0 a 5 anos utiliza o jogo e as brincadeiras como prática pedagógica diária, defendendo seu uso como um excelente recurso à aprendizagem e desenvolvimento das crianças". O estudioso também considera que a criança de dois e quatro anos possui sua atividade motora muito ativa, gosta de correr, pular, arrastar, puxar e empurrar, e, em relação à linguagem, há uma melhor organização, o que permite à criança falar mais facilmente, articulando melhor as palavras.

De acordo com Piaget (1988), é a partir dos dois anos que a criança se refere às pessoas e objetos pelo nome. Justamente nessa atividade há um aumento considerável de seu vocabulário, e ela é mais sociável nessa faixa de idade. Contudo, o sentimento de posse que adquire em relação aos seus brinquedos começa a aparecer e sua energia, exuberância, imaginação e curiosidade estão a toda força. Diante do exposto até aqui, vale ressaltar que o aprendizado que uma brincadeira permite é basilar para a formação e desenvolvimento global da criança em todas as etapas de sua vida. Daí a importância do brincar e o cuidado também que se deve ter, para com os jogos e brinquedos não estimular a imitação gestual mecânica e estereotipada que são apresentadas às crianças (Brasil, 1998).

Portanto, o jogo e a brincadeira são ferramentas básicas da vida psíquica da criança. Sendo que a criança busca o jogo também como uma necessidade e não apenas como uma distração. Assim, no jogo é que a criança demonstra suas boas e más ações, sua habilidade, seu caráter, sua vocação, ou seja, tudo que ela apresenta de oculto no seu eu em processo de formação, tornando-se visivelmente aparente na execução de jogos e brincadeiras pela criança. Sendo assim, Piaget (1978, p. 86) destaca que:

[...] os jogos são caracterizados em três grandes tipos: jogos de exercícios ( 0 a 2 anos), jogo simbólico (2 a 6 anos) e jogo de regras (6 anos em diante). É a função que vai diferenciar esses jogos que não têm outra finalidade a não ser o próprio prazer do funcionamento. Jogos de exercício: é a primeira forma de jogo que a criança conhece e aparece antes do desenvolvimento verbal completo. [...] O jogo simbólico é de certa forma, uma maneira de a criança comunicar ao outro aquilo que sente, Jogo de regras: é caracterizado pelo conjunto de leis que é imposto pelo grupo. Dessa forma, necessita de parceiros que aceitem o cumprimento das obrigações definidas nas regras. É um jogo estritamente social.

Utilizamos a teoria de Piaget devido à evolução do pensamento simbólico, que está na fase do estágio pré-operacional no qual a criança vai evoluindo gradualmente acompanhada do crescente entendimento "[...] de identidade, espaço, causalidade, categorização e número. E utilizar as funções simbólicas que a capacita no uso das representações mentais, como por exemplo: a brincadeira do faz de conta" brincadeira está muito utilizada nos espaços da Educação Infantil (Papalia et al, 2006, p. 284).

Assim, as atividades de jogos e brincadeiras nas instituições de Educação Infantil apresentam muitos benefícios para o processo de ensino e aprendizagem, são subsídios para a ampliação do conhecimento das crianças, todavia, compete aos/às 
professores/as instituírem sugestões pedagógicas que incorporem o aprendizado e o divertimento que o jogo e brincadeira podem proporcionar para as crianças.

Outro importante teórico abordado neste artigo é Vygotsky (1998) o qual descreve a importância da psicologia histórico-cultural, a qual defende que o sujeito se constitui a partir das relações com o/a outro/a. E para o autor a brincadeira infantil adquiriu uma posição privilegiada para a constituição deste sujeito de modo que, "[...] o desenvolvimento humano é forjado por processos psicológicos superiores, onde a psique-humana é essencialmente social” (Vigotsky, 1998, p. 32).

Vygotsky (1998, p. 127) ainda descreve sobre a importância do brincar quando alerta que "A criança vê um objeto, mas age de maneira diferente em relação ao que vê. Assim, é alcançado uma condição que começa a agir independentemente daquilo que se vê" ou seja, nas brincadeiras a criança pode dar outros sentidos ao que vê nos jogos, objetos dependendo de sua imaginação, possibilitando a criança transformar e produzir novos significados com seus pares.

Deste modo, Santos (1995) sinaliza a importância do brincar como uma atividade natural da criança. Quando afirma que:

O brincar é, portanto, uma atividade natural, espontânea e necessária para criança, constituindo-se em uma peça importantíssima a sua formação seu papel transcende o mero controle de habilidades. É muito mais abrangente. Sua importância é notável, já que, por meio dessas atividades, a criança constrói o seu próprio mundo (Santos, 1995, p.4).

Quando a criança brinca, ela constrói o seu mundo, é no brincar que demonstra sua percepção de mundo, e faz sua escolha da simulação da realidade vivenciada por si. Almeida (1978) e Kishimoto (2016) ainda expõem que os jogos não devem ser fins, mas meios, devem ser aplicados para o benefício educativo. A importância do brincar mesmo sendo bastante amplo seu entendimento, não precisa ser considerado somente os brinquedos criados pelo/a adulto/a, mas que possa conceber nas brincadeiras infantis, a própria produção dos materiais realizados por ela. Ou seja, no espaço da Educação Infantil, o/a docente deve perceber os jogos, as brincadeiras com propósitos e não somente o jogar por jogar. Sendo assim, Ruiz (2003, p. 63) escreve que:

O papel dos profissionais de educação necessita ser repensado. Esses não podem mais agir de forma neutra nessa sociedade de conflito, não pode ser ausente apoiando-se apenas nos conteúdos, métodos e técnicas, não pode mais ser omisso, pois os alunos pedem uma posição desses profissionais sobre os problemas sociais, mas como alguém que tem opinião formada sobre os assuntos mais emergentes e que está disposto ao diálogo, ao conflito, à problematização do seu saber.

Assim, o/a profissional da Educação precisa pensar a criança como um ser em formação, que questiona e quer respostas. Não podemos enquanto educadores/as pensar os jogos e as brincadeiras sem um propósito. Devemos buscar um conhecimento mais amplo das possibilidades disponíveis para o desenvolvimento global da criança, no contexto social, intelectual e psicológico.

\section{Jogos, Brincadeiras e a Construção do Gênero na Educação Infantil}

Para contextualizar, vale enfatizar que a construção da identidade da Educação Infantil se deu a partir do século XIX por meio das políticas de atendimento à infância, atendimento este marcado pela diferenciação da classe social. Para as crianças pobres era oferecido um assistencialismo social, compreendendo apenas o cuidar, "e o educar como experiência de promoção intelectual reservada a grupos socialmente privilegiados" (Brasil, 2013, p. 81). E por muito tempo não havia uma política que amparasse a Educação Infantil e muito menos houvesse investimento público e profissionalização nessa área. 
Destacamos que a Constituição da República Federativa do Brasil (Brasil, 1988), o Estatuto da Criança e do Adolescente (Lei 8.069/90) (Brasil, 1990), a Lei de Diretrizes e Bases da Educação Nacional (Lei nº. 9.394/1996) (Brasil, 1996), o Plano Nacional de Educação (Lei no. 13.005/2014) (Brasil, 2014) asseveram que independente de sua classe, grupo social, credo religioso, etnia... é direito de todas as crianças a Educação. Tais documentos mostram que é fundamental a organização e avaliação de Políticas Públicas a fim de buscar garantir o estudo formal às crianças, de modo planejado, tendo garantida a qualidade, $o$ acesso e a permanência.

A Lei de Diretrizes e Bases da Educação Nacional (Brasil, 1996, art. 29) regulamenta a Educação Infantil como a primeira etapa da Educação Básica e tem como finalidade o desenvolvimento integral da criança em seus aspectos físico, afetivo, intelectual, linguístico e social, de forma a completar a ação da família e da comunidade. Portanto, a criança é considerada um ser social de direitos, que interage com o mundo a sua volta, e de acordo com sua concepção e potencialidades, ela brinca de forma espontânea e involuntariamente do ambiente que vive.

$\mathrm{Na}$ Educação Infantil as propostas curriculares reconhecem e valorizam as crianças em suas peculiaridades étnicas, de gênero, cultura podendo partir de suas próprias realidades, suas experiências. O direito a uma Educação Infantil de qualidade inclui a discussão de gênero, pois neste ambiente, que é a escola, é onde se dará as relações e a vida social dessas crianças, de forma que se relacionarão com outras crianças oriundas de diversas classes sociais, religiões e etnias com valores e comportamentos também diferenciados, mesmo que este tema 'gênero' ainda seja de "pânico moral" (Maio \& Oliveira \& Peixoto, 2020, p. 57).

O assunto sobre gênero é bastante complexo, o qual exige muita informação, reflexão, cientificidade, assim pautaremos essas informações e argumentações quanto ao estudo de gênero na Educação Infantil nos documentos oficiais como, por exemplo, o artigo segundo do Plano Nacional de Educação (PNE) (Brasil, 2014) que aponta como diretriz superar as desigualdades educacionais e erradicar todas as formas de discriminação. Na Lei nº 9.394/96 (Brasil, 1996), o artigo primeiro descreve que a Educação é compreendida como processo de formação humana, e no artigo segundo é destacado que a Educação é dever da família e do Estado, tendo como finalidade o pleno desenvolvimento do/a educando/a, em seu processo de preparação para o exercício da cidadania e qualificação para o trabalho. Quanto aos princípios do artigo terceiro (Brasil, 1996), o ensino terá como base:

$\begin{array}{cl}\checkmark & \text { Igualdade (acesso e permanência); } \\ \checkmark & \text { Liberdade; } \\ \checkmark & \text { Pluralismo de ideias; } \\ \checkmark & \text { Tolerância; } \\ \checkmark & \text { Coexistência- público/privado; } \\ \checkmark & \text { Gratuidade do ensino público; } \\ \checkmark & \text { Valorização do/a profissional; } \\ \checkmark & \text { Gestão democrática; } \\ \checkmark & \text { Padrão de qualidade; } \\ \checkmark & \text { Valorização extraescolar; } \\ \checkmark & \text { Escola-trabalho-práticas }\end{array}$

Para que esses princípios sejam enfrentados na escola, é preciso entender as questões de Identidade de Gênero (as questões de gênero estão imbricadas com a sexualidade, contudo, abordaremos somente a questão de gênero) são fundamentais. A Educação Infantil como primeira etapa da Educação Básica, visa o desenvolvimento integral da criança de 
até os cinco anos em todos os seus aspectos: físico, psicológico, intelectual e social, e estes serão complemento da ação da família e da comunidade (Brasil,1996).

Quanto aos direitos dos/as pais/mães ou responsáveis, o artigo 53 afirma que eles/as têm o direito a ter conhecimento do processo pedagógico e participar da definição da proposta educacional, contudo, compreende-se que a família não definirá a proposta pedagógica (Brasil, 1990). Escola e família harmonicamente juntas na formação da criança (aqui compreendemos que dessa forma é trabalhar em rede) deixando evidente que trabalhar as questões de gênero na escola não é para destruir a família, ou confundir a identidade das crianças. Pelo contrário: as discussões referentes aos aspectos de gênero servem para ampliar a compreensão acerca do respeito entre homens e mulheres, meninos e meninas, destacando que a mulher não é inferior ao homem, mostrando que nem os meninos e nem as meninas podem sofrer violência por serem o que são.

Mais uma legislação para se ter argumento é a própria Organização Curricular para a Educação Infantil nas Diretrizes Curriculares Nacionais para a Educação Infantil - DNEI (Brasil, 2010), que destaca os princípios 1 - Princípios da Educação Infantil; 2 - Cuidar e Educar; 3 - Interações e brincadeiras; 4 - Seleção de práticas, saberes e conhecimentos; 5 - Centralidade das crianças, como forma de sustentar o respeito aos direitos fundamentais das crianças e na garantia de uma formação integral orientada para as diferentes dimensões humanas. Desta forma, até o momento com o exposto, enquanto legislação têm-se amparo para trabalhar as questões de gênero, sexualidade, educação sexual quanto forma de proteção e enfrentamento das mais variadas violências.

Por mais que haja ainda resistência da sociedade, políticos/as e até um despreparo de professores/as quanto a discussão sobre gênero desde a Educação Infantil, há a necessidade de viabilizar a participação de especialistas para trabalhar de forma segura e científica a temática proposta neste projeto, e com isso, incluir no próprio Projeto Político-Pedagógico (PPP) as decisões quanto as questões de gênero. Para Libâneo (2013) o PPP é o projeto que representa a oportunidade da direção, coordenação pedagógica, professores/as e a comunidade escolar para definir as estratégias na escola na educação das crianças, condições estas prevista na LDBEN (Brasil, 1996).

Louro (2011) e Rios e Dias (2020) afirmam que a escola é um espaço educativo, por onde se passam as vivências de gênero. No entanto, "[...] fica perceptível a necessidade de problematizar as questões que se entrecruzam a diversidade de gênero [...] nas práticas de currículo" (Rios \& Dias, 2020, p. 7), de modo a problematizar as práticas que vêm acontecendo no interior das instituições escolares; é fundamental que - pelo fato de receber crianças diversas - a escola traga para o centro do debate as diferenças existentes entre as pessoas, ensinando a não violentar qualquer ser humano por conta de características de gênero, sexualidade, diversidade religiosa, etnia etc. Desta forma, é necessária a luta contra um currículo que ainda impõe um modelo machista, reprodutor de desigualdades e modelos heteronormativos que vem determinando o lugar de meninos e meninas.

Quanto as resistências negativas vindo da esfera política, trazemos uma matéria do UOL (2020) onde o ministro Luiz Roberto Barroso do Supremo Tribunal Federal - STF decidiu que lei inspirada no Escola sem Partido é inconstitucional, ou seja, qualquer tentativa de vereadores/as, deputados/as estaduais de querer criar leis que proíbam a discussão de gênero nas escolas é considerada ilegal “[...] as ações envolvendo as discussões de sexualidades, gêneros e corporeidade estão subordinadas ao amparo legal na legislação" (Carvalho, 2020, p. 14). Todavia, a viabilidade da Educação Sexual proporcionará de forma científica, assuntos como a questão de gênero num contexto da Educação Infantil (Furlani, 2016).

Segundo Furlani (2016), assuntos como: Partes do corpo de meninos e meninas; Linguagem científica e familiar (Exemplo: vulva, pênis); Noções de higiene pessoal... isso tudo tem relação com a corporeidade, disciplina, autonomia e assim deve culminar para o cuidado com a não violência sexual; Conceitos de nudez e privacidade; Conhecer os arranjos familiares; Respeito às diferenças identitárias; Igualdade entre meninos e meninas; Coeducação; Brinquedos infantis compartilhados, visando o rompimento de paradigmas de que há essa divisão. O brincar é importante para a socialização, o processo de 
aprendizagem sobre gênero, relações de identidades, assuntos estes pertinentes de linguagem acessível ao público da Educação Infantil.

Dessa maneira, quanto maior o número de brincadeiras infantis implantadas nas atividades pedagógicas, maior será a ampliação do conhecimento da criança. Por isso, para que os objetivos sejam atingidos, devemos respeitar cada fase do desenvolvimento da criança, pois é um sujeito histórico e de direitos que se desenvolve nas interações, relações e práticas a elas disponibilizadas. Ou seja, devemos apresentar para as crianças um número vasto de brincadeiras para que sua visão de mundo seja ampliada.

Por meio dessas condições e contextos culturais, a criança faz amizade, brinca com água ou terra, faz-de-conta, deseja, aprende, observa, conversa, experimenta, questiona e assim vai construindo sentidos sobre o mundo e suas identidades tanto pessoais quanto coletivas, seja com outro ser humano ou com objetos. Essa experimentação é basilar para o desenvolvimento integral da criança, ao passo que as várias possibilidades coadunam para propiciar um crescimento mais saudável e completo.

Quanto à construção de sua identidade, buscamos articular aos estudos de gênero como instância que contribui para a formação de meninas e meninos. No que se refere às identidades de gênero, Louro $(2011$, p. 11) afirma que "[...] as identidades de gênero e sexuais são compostas e definidas por reações sociais, elas são moldadas pelas redes de poder de uma sociedade". Nesse sentido, cada sociedade tem impregnada em sua cultura e meio social, aspectos ligados às questões de gênero. É preciso que a ciência - sobretudo a partir das instituições escolares - desenvolvam ações críticas a fim de trabalhar com as crianças (desde as idades menores) a diversidade humana, enfatizando que cada pessoa tem a sua especificidade e que não pode sofrer preconceito ou violência por conta disso. Como exemplo, é urgente que as escolas discutam - em seus currículos, seus planos de aula, seus Projetos Políticos-Pedagógicos, suas reuniões com os responsáveis pelas crianças etc. - que a mulher não é inferior ao homem, além da objetificação tão acentuada do corpo feminino na sociedade ocidental. Discussões como essas desde cedo - acabam por contribuir no pensamento crítico de equidade entre as pessoas, independente do seu gênero.

De acordo com Felipe (2013, p. 56), a identidade do ser humano perpassa pelo corpo, “[...] corpos masculinos e femininos não têm sido percebidos e valorizados da mesma forma. Em nossa cultura os corpos constituem-se no abrigo de nossas identidades (de gênero, sexuais e de raça)”. Compreende-se desta forma, que há uma hierarquização do masculino com relação ao que é feminino, nas relações dos brinquedos dirigidos às meninas, percebemos que há um investimento nos quesitos para beleza ou afazeres domésticos; para os meninos estes são sempre voltados ao externo como carros, motos, profissões, como bem destaca Guerra (2005, p. 67):

As questões de gênero aparecem claramente quando os brinquedos são descritos e sugeridos de acordo com a idade das crianças e são apresentados para demarcar os lugares sociais das mulheres e dos homens. As meninas são posicionadas, através da brincadeira, como donas de casa ou mães, estando assim, ligadas ao espaço privado. Já os meninos, aprendem a valorizar o espaço público, a terem uma profissão e a valorizarem o desenvolvimento físico.

Esta compreensão se dá devido ao brincar e as brincadeiras estarem atreladas a compreensão da separação e da diferenciação por gênero, ou seja, brinquedos tidos como de meninas e de meninos e assim a sociedade vai constituindo os sujeitos e a escola por sua vez até em reproduzir estes efeitos (Felipe, 2013). É preciso que a escola barre a propagação de ideias preconceituosas e estereotipadas em relação às questões de gênero. Se torna fundamental que as práticas pedagógicas ao partir da realidade local - defendam que homens e mulheres têm capacidades cognitivas, físicas e mentais para realizar variadas atividades, sem inferiorizar uma em detrimento do outro. Quando uma criança passa a questionar os tabus sociais, a compreensão da realidade acaba por se construir de uma forma mais igualitária e menos violenta. Aqui ainda valem os escritos de Oliveira, Peixoto e Maio (2018, p. 38) quando ressaltam que a “[...] escola, enquanto instituição social, tem muita influência 
no combate a todas as formas de violência, portanto, precisa estar organizada em documentos e demais instrumentos, a fim de contribuir para uma cultura de paz".

Entendemos por gênero o embasamento de Louro (2000) e Meyer (2013) quando especificam que se trata de um conjunto de concepções e normas sobre o que é identificado como masculino ou feminino em determinado contexto cultural e em determinado tempo, e enquanto as concepções que implicam nas relações de poder no que se refere aos corpos e nas identidades de gênero e sexuais, ou seja, ao longo da vida vamos nos constituindo como homens e mulheres, num processo que não é linear. Esse processo é complexo e com muitas rupturas, portanto delega estudo científico para sua melhor compreensão.

Meyer (2013) ainda destaca a necessidade dos estudos de gênero a fim de desconstruir as práticas de segregação entre meninos e meninas, incluindo as ações de brincar e jogar. Para a autora, o conceito de gênero propõe "[...] um afastamento de análises que repousem sobre uma ideia reduzida de papéis/funções de mulher e de homem” (Meyer, 2013, p. 20). Desse modo, é fundamental discutir a produção de diferenças e de desigualdades quanto os jogos e as brincadeira na construção do gênero no contexto da Educação Infantil e que os processos sociais estão imbricados em marcar e discriminar esses momentos lúdicos vivenciados.

Pereira e Oliveira (2016) ressaltam - em sua pesquisa com crianças da cidade de Maceió-AL - que os significados, ressignificados sobre ser homem ou mulher, são transmitidos às crianças no contexto familiar e dentro da escola. E que nessas instâncias, as representações de masculino e feminino são formadas, ou negadas, desde a infância. Logo, a escola - que deveria ser ambiente de estudo de ciência - muitas vezes acaba por reproduzir os tabus encontrados na sociedade. Embora seja uma tarefa árdua e complexa, é preciso que os/as trabalhadores/as escolares tenham acesso à formação adequada, a fim de quebrar com o ciclo da manutenção dos preconceitos. Para isso, os documentos oficiais, conforme destaca Autor (2017), precisam trazer em suas páginas ações que contemplem discussões e práticas acerca das relações de gênero. Junto a isso, é urgente que se estabeleça a vontade política a fim de fazer valer o que está disposto nas leis oficiais, com o intuito de discutir de forma planejada e articulada com a realidade, os aspectos ligados aos estudos de gênero.

A brincadeira e os jogos no contexto da Educação Infantil, estão imbricados nas representações de gênero, conforme destaca Pereira e Oliveira (2016, p. 275)

Podemos destacar que as diferenciações entre homens e mulheres, meninos e meninas, são demarcadas e disseminadas tanto pela família quanto pela escola nos meandros da cultura, criando muitas vezes, padrões comportamentais distintos da masculinidade e feminilidade que se inscrevem nos corpos e incidem nos modos de ser de cada indivíduo. [...] a construção de diferenciação entre os gêneros inicia-se antes mesmo do nascimento e passa a ganhar mais força nas primeiras relações das crianças no ambiente coletivo da Educação Infantil.

Este acontecimento quanto ao desenvolvimento e aprendizagem das crianças na construção do gênero no espaço escolar é decorrente de ser um espaço de regras, regimentos e do controle do tempo, pois a escola, separa e institui, no qual as relações de gênero estão implicadas também em relação de poder (Louro, 2011). A mesma autora ainda acrescenta e alerta que as atitudes de muitos/as professores/as podem reforçar, contribuir para costumes machistas e sexistas, não sendo positivo estes valores na vida das crianças. Pois cada vez que se reforça a segregação entre meninos e meninas para as brincadeiras e jogos, se reforça um preconceito velado, propagado "naturalmente" tanto pelos/as responsáveis, como também pelos/as professores/as.

\section{Algumas Considerações}

Foi objetivo deste manuscrito analisar - a partir de uma pesquisa bibliográfica e documental - acerca da função dos jogos e das brincadeiras na prática educativa da Educação Infantil, bem como a contribuição destes na construção do 
desenvolvimento e aprendizagens sobre gênero. Esse assunto, embora ainda seja um tabu recorrente em nossa sociedade, precisa ser desmistificado e encarado de frente nas práticas pedagógicas, a partir do planejamento e da cientificidade, adequando as ações a cada idade/ano escolar.

Concluímos, ainda, que a criança não nasce sabendo brincar, ela precisa aprender por meio das interações com outras crianças e com os/as adultos/as. Ela descobre com os objetos e brinquedos, a dar significado à realidade vivenciadas. Além disso, com intervenções ela aprende novas brincadeiras e suas regras. Com isso, o brincar não deve ser compreendido na Educação Infantil nem tão pouco no Ensino Fundamental como um conhecimento pronto e por isso reproduzido em manuais, é preciso que o brincar seja concebido como uma linguagem que fala do/a próprio/a brincante, permitindo a criança ser autora de sua fala e de seus atos.

O brincar carrega as experiências, as vivências, enfim, a história de cada criança enquanto sujeito, como ser histórico e social. Contudo, as instituições escolares devem possibilitar espaços físicos e simbólicos para a vivência do jogo pelas crianças, onde todos/as possam ser envolvidos/as. Os/As professores/as precisam perceber a importância dos jogos e do brincar no processo de ensino e aprendizagem.

E nesta perspectiva de desenvolver de forma integral a criança, podemos considerar o/a professor/a como um/a agente de transformação, pois, ele/a é responsável por nortear a trajetória de seus/suas alunos/as, podendo ser técnica, metodológica e teórica. Sendo assim, é preponderante que o/a docente e todos/as que fazem parte da Educação tenham uma consciência crítica. Ou seja, precisam questionar de forma crítica as políticas educacionais e se despregar de concepções conservadoras (Ruiz, 2003).

Dessa forma, o/a professor/a precisa ter em mente que, quando parte do princípio de atividades voltadas ao conhecimento e experiências vivenciadas por seus/suas alunos/as, essas atividades tornam-se significativas e de fácil compreensão pelos/as mesmos/as. Ou seja, todo esse processo de ensino e aprendizagem favorece o entendimento do que está sendo ensinado, por meio da relação da escola com o cotidiano da criança.

Assim, a brincadeira é capaz de produzir na criança a vivência do lúdico e o reconhecimento de si mesma, desenvolvendo o seu potencial criativo. Deste modo, a brincadeira é percebida como uma atividade que, além de produzir o desenvolvimento amplo das crianças, estimula a intercâmbio entre os pares, a resolver de forma construtiva os conflitos, a formação de um/a cidadão/cidadã com senso crítico e reflexivo. Desta forma, nesse artigo, compreendemos que o brinquedo é um instrumento em que a criança pode expressar sua realidade interna, de forma que cada uma usa o brinquedo e o jogo de acordo com sua própria imaginação.

Se reconhece que quando um menino brinca com uma boneca, ou quando uma menina brinca com carrinhos, eles/as ganham a chance de aprender que bebês precisam de cuidados e zelos, que cuidar de pequenos/as requer responsabilidades, e que o menino ao brincar com bonecas não o fará menos ou mais heterossexual. Isso, o ajudará a entender que as meninas não têm um instinto nato para o cuidado, para as atividades domésticas, apenas the foram ensinadas a cuidar desde muito cedo e com isso, ele próprio pode, e deve cuidar também, e com isso, quebrar paradigmas de que exista, brinquedos de meninas e brinquedos de meninos, ou na pior das hipóteses, o rosa é de meninas e o azul é de meninos.

Contextualizar o tema sugerido neste artigo no ambiente escolar, se deu devido, o preconceito ainda existente ao falar de gênero ser perturbador e quase que proibido na Educação Infantil devido às práticas sexistas perpassarem neste ambiente educacional. E este espaço infantil contribui bastante na sustentação dos estereótipos quanto separar o que é para meninas ou para meninos, ou seja, designar objetos, cores, brinquedos, roupas sendo deles ou delas. Isso distorce a compreensão da realidade das crianças, impedindo-as de explorar suas escolhas sem julgamentos.

Compreendemos, nesse sentido, que a Educação tem um papel preponderante na formação humana, de modo que deve sempre estar pautada por práticas científicas, buscando contribuir para o crescimento pessoal, mental, físico e intelectual das 
crianças. Assim, a partir de práticas não-sexistas, não-machistas, não-racistas, não-LGBTfóbicas, não-violentas, conseguirá contribuir em seu papel social, promovendo uma cultura de paz (Márcio \& Peixoto \& Maio, 2018). E essas práticas precisam iniciar desde a Educação Infantil, por meio dos jogos e das brincadeiras: artefatos muito presentes nessa etapa da Educação.

Contudo, é preciso atentar o olhar de que o brincar e os jogos não são artefatos somente para o divertimento, entretenimento, mas também, merecem um olhar crítico, devido fazer parte do cotidiano das crianças. A utilização dessas práticas deve servir para demonstrar que meninos e meninas são capazes de realizar diferentes ações, além disso, é possível o trabalho para alcançar a equidade de gênero, ao passo que um jogo ou uma brincadeira tem o poder de fazer com que uma criança se coloque no lugar da outra, reflita sobre a realidade cultural e social, compreenda que as pessoas não podem sofrer preconceito ou violência. Parece apenas divertido, mas também se trata de uma responsabilidade social.

\section{Referências}

Almeida, P. N. (1978). Dinâmica lúdica jogos pedagógicos. Loyola.

Ariès, P. (1981). História social da criança e da família. Guanabara.

Bogdan, R., \& B, S. (1982). Qualitative research of education. Allyn and Bacon.

Brasil. (1988). Constituição da República Federativa do Brasil.1988. http://www.planalto.gov.br/ccivil_03/constituicao/constituicao.htm

Brasil. (1998) Referencial Curricular Nacional. http://portal.mec.gov.br/seb/arquivos/pdf/rcnei_vol1

Brasil. (2013). Diretrizes Curriculares Nacionais Gerais da Educação Básica. Brasília: MEC, SEB, DICEI.

Brasil. (1996). Lei de Diretrizes e Bases da Educação Nacional. Lei de no 9.394/96 de 20 de dezembro. Brasília: Presidência da República. http://www.planalto.gov.br/ccivil_03/leis/19394.htm

Brasil. (1990). Estatuto da Criança e do Adolescente. Lei nº 8.069/90. CBIA-SP.

Brasil. (2014) Plano Nacional de Educação. Brasília: Presidência da República. http://www.planalto.gov.br/ccivil_03/_ato2011-2014/2014/lei/113005.htm.

BrunellI, R. P. (1996). O jogo como espaço para pensar. Papirus.

Cambi, F. (1999). História da Pedagogia. Fundação Editora UNESP.

Carvalho, F. A. (2020). Para além de "meninas vestem rosa, meninos vestem azul”: as conjunturas e as ideologias nos novos rumos da educação para os gêneros e as sexualidades. Revista Educação, Santa Maria, (v. 45). https://periodicos.ufsm.br/reeducacao

Felipe, J. (2013). Erotização dos corpos infantis. In: Louro, G. L., Felipe, J., \& Goellner. S. V. (Orgs.). Corpo, gênero e sexualidade: um debate contemporâneo na educação. (9. Ed). Petrópolis, RJ: Vozes, 54-66.

Finco, D. (2010). Brincadeiras, invenções e transgressões de gênero na educação infantil. Revista Múltiplas Leituras, São Paulo, (v. 3, n. 1), 119-134, < https://www.metodista.br/revistas/revistasims/index.php/ML/article/view/1905/1908>.

Gil, A. C. (2002). Como elaborar projetos de pesquisa. (4a ed). Atlas.

Guerra, J. (2005). Dos “segredos sagrados": gênero e sexualidade no cotidiano de uma escola infantil. Dissertação (Mestrado em Educação). 128 fls. Universidade Federal do Rio Grande do Sul: UFRGS, Faculdade de Educação, Porto Alegre.

Kishimoto, T. M. M. (1992). Jogo, a criança e a educação. Universidade de São Paulo.

Kishimoto, T. M. M. (2016). Jogo, a criança e a educação. Ed. rev. Cengage Learning.

Kishimoto, T. M. (2014). Jogos, brinquedos e brincadeiras no Brasil. Espacios em Blanco. Revista de Educación, (n. 24), 81-105,

Kuhlmann JR., M. (2000). História da Educação Infantil Brasileira. Revista Brasileira de Educação. (n. 14). 5-18. https://www.scielo.br/pdf/rbedu/n14/n14a02.pdf

Libâneo, J. C. (2013). Organização e gestão da escola: teoria e prática. (6. Ed.). Ampl. Heccus.

Louro, G. L. (2011). Gênero, sexualidade e educação - uma perspectiva pós estruturalista. (12a ed). Vozes.

Louro, G. L. (2000). Pedagogia da sexualidade. In: Louro, G. L (Org.). O corpo educado: pedagogias da sexualidade. (2. Ed.). Belo Horizonte: Autêntica, 734.

Meyer, D. E. (2013). Gênero e educação: teoria e política. In: LOURO, Guacira Lopes; FELIPE, Jane; GOELLNER, Silvana Vilodre (Orgs.). Corpo, gênero e sexualidade: um debate contemporâneo na educação. (9a ed.). Vozes, 11-29. 
Research, Society and Development, v. 10, n. 2, e13610212489, 2021

(CC BY 4.0) | ISSN 2525-3409 | DOI: http://dx.doi.org/10.33448/rsd-v10i2.12489

Maio, E. R., Oliveira, M. \& Peixoto, R. (2020). Discussão sobre gênero nas escolas: ações e resistências. Revista Retratos da Escola, 14(28), 57-74. http://retratosdaescola.emnuvens.com.br/rde.

Oliveira, A. M. (2012). Ludicidade na Educação Infantil: a importância na educação de crianças de 4 a 5 anos. Londrina: UEL. http://www.uel.br/ceca/pedagogia/pages/arquivos/2012\%20ANELIZE\%20MOREIRA\%20DE\%20OLIVEIRA.pdf

Oliveira, M. (2017). Políticas públicas e violência sexual contra crianças e adolescentes: Planos Municipais de Educação do Estado do Paraná como documentos de (não) promoção da discussão. 136f. Tese (Doutorado em Educação) - Universidade Estadual de Maringá. Maringá.

Oliveira, M.; Peixoto, R., \& Maio, E. R. (2018). A Educação enquanto promotora de uma cultura de paz: o foco nas questões de gênero e sexualidade. Revista Amazônida, Manaus, 03(2), 27-39. http://www.periodicos.ufam.edu.br/amazonida/article/view/4893/4181

Papalia, D., \& Feldman. R.D. (2006). Desenvolvimento Humano. (8). D. Bueno, Trad. Artmed.

Pereira, A. S. O., \& Ericka , M. B. (2016). Brincadeiras de meninos e meninas: cenas de gênero na Educação Infantil. Revista Reflexão e ação, Santa Cruz do Sul, 24(1), 273-288. https://online.unisc.br/seer/index.php/reflex/article/view/7061

Piaget, J. O. (1978). Nascimento da inteligência na criança. (1). Zahar.

Pinto, M. (1997). A infância como construção social. In: PINTO, Manuel; SARMENTO, Manuel Jacinto (Orgs.). As crianças: contextos e identidades. Minho: Universidade do Minho. Centro de Estudos da Criança. 33-79.

Rios, P. P. S., \& Dias, A. F. (2020). Currículo, diversidade sexual e de gênero: tecendo reflexões sobre a formação docente. Reasearch, Society and Development, $9(10)$. 1-23. https://dx.doi.org/10.33448/rsd-v9i10.7572

Rocha, R. C. L. (2002). História da infância: reflexões acerca de algumas concepções correntes. ANALECTA Guarapuava, Paraná, 3(2), 51-63.

Rousseau, J. J. (1999). Emilio ou da educação. Martins Fontes.

Ruiz, M. J. F. (2003). O papel social do professor: uma contribuição da filosofia da educação e do pensamento freireano à formação do professor. Revista Iberoamericana de Educación. Santa Cruz de la Sierra/Bolívian. (33). 55-70. https://rieoei.org/historico/documentos/rie33a03.PDF

Santos, S. M. P. (1995). Brinquedoteca: sucata vira brinquedo. Artes Médicas.

Schwartz, G. M. (1998). O processo educacional em jogo: algumas reflexões sobre a sublimação do jogo. Licere, Belo horizonte, 1(1), 66-76.

Sommerhalder, A. (2011). Jogo e a educação da infância: muito prazer em aprender. Curitiba, PR: CRV.

UOL. STF decide que lei inspirada no Escola sem Partido é inconstitucional. (2020). Do UOL em Brasília. Do UOL em São Paulo. https://noticias.uol.com.br/politica/ultimas-noticias/2020/08/21/stf-tem-maioria-contra-lei-de-alagoas-inspirada-no-escola-sem-partido.htm

Valentim, E. C. C. (2019). O Processo de Aprendizagem através de Jogos, Brinquedos E Brincadeiras Para Crianças Com Necessidades Especiais. Educar FCE, São Paulo, 18(01), 785-799. https://www.fce.edu.br/pdf/ED18-FINAL-03.pdf

Vigotsky. L. (1998). A formação social da mente. Martins Fontes. 